\title{
Color Performance of Chinese Flower-and-Bird Fine Brushwork
}

\author{
Liang Kui \\ Art College of Southwest University for Nationalities, Chengdu, Sichuan, China \\ 59624917@163.com
}

Keywords: fine brushwork, flower-and-bird, color performance

\begin{abstract}
As the main element of the flower-and-bird fine brushwork, color performance plays an important role in the painting language. Chinese contemporary fine brushwork flower and bird painting absorbs the traditional experience and advanced foreign technology in the color performance, forming its own unique artistic charm. This paper expounds the features, formation and realization of color performance of Chinese flower-and-bird fine brushwork in order to provide reference for the painters of flower-and-bird fine brushwork.
\end{abstract}

\section{Features of Color Performance of Chinese Flower-and-Bird Fine Brushwork}

Chinese contemporary Flower-and-Bird Fine Brushwork has distinctive artistic characteristics, such as categorization, lyricism and decoration.

Categorization. As one art form of traditional Chinese painting, the flower and bird Fine brushwork painting has a unique color performance system. The proverb "drawing color adheres to the type" summarizes an important color feature of traditional flower and bird fine brushwork. With the type of color is in accordance with the description of the object originally color design color, but not on the real copy. Painters in the observation of the actual color images based on, give full play to the subjective initiative, through its properties of color images of cognition and emotion experience, according to the needs of the screen of color were summarized, and draw a conclusion that the color is the result of subjective and objective interaction. The types of color change and transfer regularity of the nature of the color attribute. Understanding and grasping on this property is mainly from the images of the experiences accumulated in the daily life of people. For example, summer grass will not be show as the yellow color because of the influence of solar light intensity in a local black. With the type of color is in accordance with the different properties of different color images to give color constancy. At the same time, its colors with the natural world view of people an ideal aesthetic attitude. Winter to spring, all things recovery, spit willow green, showing a sent an angry, this spring scene that is constant attributes, it brings our inner video is a germination of green. With the intention of release for based on the objective description of the object, belongs to the object. But people are different from the emotional animal. It has subjective initiative in understanding and transformation of things. It also can't completely depend on the objective things in the process of running, if the correct understanding of objective things. Therefore, the artist must grasp the laws of objective things from the continual practice.

Lyricism. Chinese people have a special feeling to the natural environment which supports their material life. No matter the nature and the life, all of them have the emotional rhythm. Natural flowers and beauty of poetry and painting has become part of Chinese cultural life and spiritual life. Life of wind with dew of lotus disc however, branches fluttering birds lovable, peony flowers season can be alerted the capital, to search for orchid aroma, travels to the mountain corner. Chinese painting is to show the beauty of flowers and birds, the beauty of nature. But it is not just the performance of natural beauty, it really has a millennium is to express one's ideas with flowers and birds. In the Chinese painting in the composition of the language, the Chinese people are more adept at using its color language to convey this kind of Oriental feeling, in order to express their feelings. Various techniques, because of its point, writing, hook technique language is from calligraphy embezzle to painting to hook write in varying degrees with lyric freehand brushwork in traditional Chinese painting nature. Painting bamboo is very focused on sketching. The artist swims in the bamboo forest to observe the modal physics of bamboo, and experience the good spirit of 
bamboo. It firstly used the ink surface, with the tiny ink, superb tricks and elegant ink drawings. The bamboo has the natural form and lyric feelings.

Decoration. Decorative color is based on the beauty, with the color beauty as the medium. It not only focuses on the color beauty performance, but also emphasizes the artist's intention and artistic conception. It is not affected by the shackles of the natural color, light does not emphasize the role, not the pursuit of strong sense of three-dimensional, space, to seek changes in the pure plane, color contrast and harmony principle based the discoloration or change the color, the color of a kind of nonrealistic idealized, advocate "intended to nature" has the characteristics of simple, romantic, exaggerated. The use of Chinese painting pigments also determines its decoration property of the flower and bird painting in the early era. Painters began to use only monochrome of mineral and plant pigments and development. Painting works is a cultural show for the times, which has become the embodiment of the culture of Chinese fine brushwork flower and bird painting. This kind of culture is to control as a whole on the whole work time and to show the spiritual and cultural, but also to fully reflect the current our country contemporary meticulous flowers and birds painting aesthetic. Screen using the two kinds of color, and the reality of color in hue differences, some heavy strong; but the color itself has the charm of color decoration. In the creation of Chinese painting, correctly handling the relationship between ink and color reflects the decoration of color performance.

\section{Formation of Color Performance of Chinese Flower-and-Bird Fine Brushwork}

The contemporary Chinese artists inherit the traditional experience and introduce the advanced foreign technology in the color performance, forming the own unique artistic charm of color performance of Chinese flower-and-bird fine brushwork.

Making the Past Serve the Present. The color is a kind of expression means of the painting form in the fine brushwork painting. As a fundamental element, the line's performance limits the development of color to a certain extent in traditional Chinese painting. As a new element, color's performance is not completely apparent in the fine brushwork of flower and bird painting. Since the Tang and Song Dynasties, meticulous flowers and birds painting in the design concept of attachment in the traditional design concept, according to the knowledge to understand the ancient painters, induces the accumulation of program color. "Rendering the type of color" means distinguishing the classification of the flower or bird, and rendering the effective color. Therefore in design mainly in ink and light color flat painted the dye forms, applying color hook filled and outline. Secondly, according to the color of different texture ink stained, pale color stained and color staining. Chinese traditional exquisite brush flower and bird painting color performance neither comparison of lightness and purity of use is different from western painting in the pursuit of showing images of light and dark. Cause the performance of things is not prominent, not enough to bring the viewer from the powerful visual impact of color. People in the anxiety and fatigue state of mind, it is necessary to find a method capable of adjusting and relaxing the body and mind, this time fine brushwork flower and bird painting with its unique close to nature become able to comfort people's spiritual world and alleviate the suffering of the public mind aftercare product and a safe haven. People are tired of using color exaggerated variation or makeup to win instant visual stimulation of the painting form. It has can give people peaceful feeling and relieve the pain of the mind.

Making Foreign Serve China. In the beginning of 20th century, a group of Chinese prominent painters returned to China, bringing the foreign culture and ideology that only the Chinese painters select the advantage of western painting language can make Chinese painting out of the rest on its laurels backwater. They brought back the western style of the scientific concept of color and drawing color and other teaching methods, the Chinese contemporary painting teaching and the art of the artists have a profound impact on the line. Realism of western paintings, the idea that the painter's brush should be like a mirror, can be reproduced placed in front of all the images of the color, if there is no such skills. It is not a really clever painter. The artists will the marriage of science and painting, formation and variation of the optical principle of in-depth research and 
analysis of color, in order to through the solution generated by the light effect on the object color changes and changes of color relationships to more accurate to shape. Many fine brushwork of flower and bird tries to reconstruct the color expressive force and realize a more ideal, more infectious - paintings, absorbing western color concept, which "light" as one of the elements of Western painting, many contemporary meticulous painters pursuit, in the creation of Chinese painting, screen that break the traditional smoothing processing, the light source color, color environment, into the picture, add to the atmosphere of the picture color, expanded the vision of beauty. Through collisions with the concept of Western color, exquisite brush flower and bird painting reform has taken a greater pace, have a new awareness of the use of color, take the advantages of Western painting, and received the essence of, expand the exquisite brush flower and bird painting. It is the core technology of the color performance of the Chinese painting color system, advancing the transformation from tradition to the modern.

\section{Realization of Color Performance of Chinese Flower-and-Bird Fine Brushwork}

Color Distribution. The aesthetic orientation of contemporary Chinese flower and bird fine brushwork is mainly reflected by the color distribution. The color distribution is an important part of the creation process of the fine brushwork flower and bird painting. In the contemporary Chinese fine brushwork flower and bird painting, pay attention to the distribution of color. Is through the science of color distribution, make the color language is full of vitality, also for our color art set aside a tremendous performance space, gives our country contemporary meticulous flowers and birds painting strong aesthetic value. Scientific distribution of color can make the color language use more flexible, and to provide a certain space for the color art, which directly increases the aesthetic value of the work. At present, our country's fine brushwork flower and bird painting will draw the focus of the pursuit of visual impact, which is a new aesthetic trend. The Chinese flower and bird paintings attaché great importance to visual stimulation through the color. It has also become the new trend of the color performance.

Color Innovation. Innovation is the basis for the development of things. The development of the Chinese flower-and-bird fine brushwork needs the innovation of color performance. Flower and bird painting brushwork color innovation reflects the characteristics of its plasticity. Take the Chinese well-known painter Jiang Hongwei for example, he is good at the color innovation and gets achievements of painting. The successful innovation depends on his solid sketch basic skill and the ability of gouache. After long-term copying Chinese traditional flower and bird paintings, Jiang Hongwei mastered the laws of color and explores the color innovation, opening the door to Chinese fine brushwork flower and bird painting color innovation. The development of anything cannot be separated from the innovation, the use of color in Contemporary Chinese fine brushwork flower and bird painting cannot be separated from the power of innovation. It is through the innovation of color, to further show the contemporary Chinese fine brushwork flower and bird painting of plasticity. Based on the coping and study, Jiang Hongwei not only forms the features of his fine brushwork, but also creates a Chinese painting color innovation road.

Color Rendering. At present, the freehand and realism of Chinese flower and bird fine brushwork mainly depends on the color rendering. Flower and bird fine brushwork will be able to vividly show the fish, birds, insects and flowers on the paper through a special form. The success of color rendering is the main means to increase its realistic and enjoyable. Freehand brushwork can better express the feelings of the author, but also able to highlight the central idea of contemporary Chinese painting. Chinese fine brushwork flower and bird painting is a real thing to show. Therefore, in the traditional Chinese fine brushwork flower and bird painting is more emphasis on its realistic. This realistic rendering of color is reflected in the most obvious. This is obviously different with our contemporary meticulous flowers and birds painting, contemporary Chinese fine brush flower and bird painting use of color rendering further emphasizes freehand brushwork of painting object to highlight our contemporary meticulous flowers and birds painting expressive effect. It has become a new breakthrough of Chinese flower and bird fine brushwork and fully reflects the main idea of the fine brushwork. 


\section{Conclusion}

Color is an important element in flower and bird fine brushwork, and the color language also has the diversity and complexity. Exploration of the color performance of contemporary fine brushwork color is multi-faceted. This paper expounds the unique characteristics, formation mechanism and realization method of the color performance of the flower and bird fine brushwork. With the progress of the times, the aesthetic aspirations are also changing. We look forward to the further practice and study of the color performance to make the flower and bird fine brushwork continuously prosperous.

\section{Acknowledgements}

Ziyi ZENG who is Art College, Southwest University For Nationalities published the paper "Black and White ,Actual Situation,Mr. Liu Pu landscape appreciation" in ISTP 《International Journal of Technology Management》 2014. N0.10 (P98-P100 ), This paper is Southwest University For Nationalities 2014 graduate degree construction projects, Project Number: 2014XWD-S0504"

\section{References}

[1] Nie Ruichen, Study on Diversified Aesthetic Orientation of Flower-and-bird Painting, Tianjin University, 2011.

[2] Li Shaoguang, Theories of Color of Chinese Contemporary Flower-and-Bird Fine Brushwork, Shandong University, 2013.

[3] Liao Huiyu, A Brief Analysis of the Development of Contemporary Meticulous Flowers-and-Birds Painting, J., Art in China, 2015(1):120-122.

[4] Wang Juan, On Flower-and-bird Painting by Wu Changsuo, Journal of Guiyang University Social Science (Quarterly), 2011(1):124-126. 